\title{
ESTUDO DA REGULAÇÃO SOCIAL EM NANNOTRIGONA (SCAPTOTRIGONA) POSTICA LATREILLE, EM DUAS COLÔNIAS (NORMAL E COM RAINHAS VIRGENS), COM ESPECIAL REFERENCIA AO POLIETISMO ETÁRIO (HYM., APIDAE, MELIPONINAE)
}

\author{
Dércio Simões e Luci Rolandi Bego \\ Universidade Estadual Paulista "Julio de \\ Mesquita Filho" - UNESP - Campus \\ Universitário de Rio Claro \\ Instituto de Biociencias
}

Departamento de Biologia (Setor de Ecologia) da Fac. Fil. Ciênc. Let. - Ribeirão Preto (USP). Endereço Atual:

Depto. de Ecologia do Instituto de Biociências da USP.

$$
\text { C.P. 11.230 - São Paulo }
$$

\section{RESUMO}

Foi estudada a divisão de trabalho entre as operárias de Nannotrigona (Scaptotrigona) postica em uma colônia normal (com rainha fisogástrica) e outra, com rainhas virgens.

Os principais fatos observados foram:

Do mesmo modo que ocorre em $A$ pis, as atividades desempanhadas pelas operárias de $S$. postica se modificam de acordo com a idade e, também, com as necessidades da cốonia. A seqüência de atividades é semelhante entre a colônia normal e aquela com rainhas virgens. A alteração mais marcante é que existe uma antecipação de algumas atividades das operárias na colonia com rainhas virgens.

A substituição da rainha fisogástrica foi observada mostrando alguns aspectos comportamentais interessantes.

Provavelmente, a aceitação da rainha em colônias de $S$. postica se dê na fase em que a mesma encontra-se virgem.

A longevidade média das operárias na colônia normal foi maior que na colônia contendo rainhas virgens. 


\section{ABSTRACT}

Age polyethism in Nannotrigona (Scaptotrigona) postica was observed by following up individually marked bees in normal (queen headed) and colonies containing virgin queens. The results we found were similar to those observed in Apis. The tasks developed by the workers are age determined, but they depend primarily upon colonial needs.

Normal colonies as well as the ones containing virgin queens have a similar task sequence. Nevertheless the colonies containing virgin queens show an antecipation in some activities when compared to normal colonies.

The substitution and killing of queen (the process is the same for physogastric or virgins) is described for the first time. There is a probability of virgin queens being accepted before the queen substitution process. Worker's mean life span is larger in normal colonies than in virgin queens ones.

\section{INTRODUÇÃO}

Alguns trabalhos sobre polietismo em abelhas têm demonstrado certa variabilidade e flexibilidade das tarefas desempanhadas pelas operárias. Mesmo assim, desenvolveu-se uma idéia bastante difundida de que as várias tarefas desempenhadas pelas obreiras são condicionadas pela idade, sendo, portanto, rigidamente determinadas. $\mathbf{E}$ importante salientar que mesmo os trabalhos clássicos, como por exemplo, aquele de Tinbergen (1953: 101-103), se refere a esse tipo de interpretação, que atualmente não é mais aceita (Sekiguchi \& Sakagami, 1966).

Nos Meliponinae foram feitas alguns pesquisas sobre divisão de trabalho (Bassindale 1955; Kerr \& Santos Neto 1956; Hebling, Kerr \& Kerr 1964; Darchen 1969; Silva 1970). Esses trabalhos demonstraram uma seqüência de tarefas desempenhadas pelas operárias, segundo faixas gradativas de idade e, também, algumas alterações que podem ocorrer na ordem da execução dessas tarefas, quando surgem modificaçбes de ordem interna na colonia.

Devido a necessidade de mais dados sobre a bionomia básica de $S$. postica e dos Meliponinae em geral, propusemo-nos a estudar a divisão de trabalho em colonia normal e compará-la com aquela que ocorre em colonia contendo rainhas virgens, substituindo à fisogástrica.

\section{MATERIAL E MÉTODOS} (MG).

Utilizamos quatro colonias de $S$. postica provenientes de Pocinhos do Rio Verde

Duas delas foram colocadas em colmeias de observação do tipo descrito por Sakagami \& Zucchi (1963) e Sakagami (1966). As outras duas foram colocadas em caixas de madeira e mantidas fora do laboratório, em condiçбes apropriadas. Todas as colonias encontravam-se em boas condiçб̋es de alimento e população.

Antes de iniciarmos a explanação relacionada à metodologia usada, conceituaremos os dois diferentes tipos de colonias utilizadas. Consideramos normal uma colonia que contém abelhas em todas as classes etárias, rainha fisogástrica, machos (não necessariamente), ovos, larvas, pupas, potes de pólen e mél e todos os materiais comumente presentes em uma colmeia. 
A colônia com rainhas virgens refere-se à uma colonia normal onde a rainha fisogástrica foi retirada e substituída por rainhas virgens.

Para o estudo da divisão de trabalho na colonia normal, introduzimos 120 operárias recém-emergidas, marcadas individualmente, através do código descrito por Sakagami (1966), em uma colmeia de observação. Essas abelhas foram observadas diariamente, por aproximadamente 4 horas (em dois perfodos de 2 horas) e todos os principais trabalhos por elas executados foram registrados, até o final das suas vidas.

Procedemos da mesma fora com a outra colonia. Apenas retiramos a rainha fisogástrica e introduzimos na colonia rainhas virgens ou casulos reais.

Além disso, colocamos uma tela excluidora de rainha na entrada da colonia, para evitar que as rainhas voassem e fossem fecundadas.

No decorrer do experimento, sempre que uma rainha virgem não era mais localizada, introduziamos outras rainhas virgens ou células reais prestes para emergirem novas rainhas.

\section{RESULTADOS}

1. Observações referentes à colônia normal.

0 estudo na colonia normal foi iniciado em 07/11/72. Das 120 operárias marcadas, 97 foram aceitas pela colonia.

No decorrer das observaçōes, ocorreu um fato novo que ainda não havia sido descrito em S. postica.

Após o 160 dia de estudo, observamos grande agitação sobre o favo de cria, onde as células estavam sendo construídas. Verificamos que a rainha fisogástrica estava sendo atacada e arrastada, muito lentamente, sobre o favo. As operárias ao seu redor encontravam-se em grande estado de agitação e tentavam colocar cerume em cima do seu corpo. Quando a rainha atingiu a extremidade do favo, onde se inicia o invólucro, as operárias começaram a cobri-la com cerume, fazendo desse modo, um amontoado deste material por todo o corpo dela. Depois de uma hora, a rainha ficou com o seu corpo completamente coberto de cerume. Observava-se apenas, uma estrutura de cerume de forma oval, aderida à uma das partes da colonia.

No dia seguinte, após a morte da rainha velha, observamos uma rainha jovem, sobre o favo. Três dias depois, já estava sendo cortejada (certamente fecundada) e, no quarto dia, já iniciava a postura nas células de cria.

Aproximadamente oito dias antes das operárias matarem a rainha velha, notamos que esta se apresentava muito vagarosa, ficando muito pouco tempo sobre o favo de cria em construção. Permanecia grande parte do tempo sobre os favos mais velhos ou no assoalho da colonia. Além disso, mesmo quando havia muitas células prontas, a rainha demorava para ir até o favo. Observamos também que, 13 dias antes da sua morte, uma rainha virgem corria por toda colonia, com várias operárias atrás dela e, freqüentemente, lambiam o seu corpo. Esta rainha aparecia várias vezes no favo em construção e nunca era hostilizada pelas operárias. Não sabemos, no entanto, se essa rainha é a mesma que substituiu definitivamente a rainha velha, morta pelas operárias. 


\section{Algumas observações referentes à colônia com rainhas virgens.}

O experimento nesta colônia iniciou-se em 05/08/73. Neste mesmo dia, colocamos uma tela excluidora de rainhas na entrada da colonia. Em 08/08, retiramos a rainha fisogástrica e introduzimos na colonia 120 operárias, individualmente marcadas. Destas, 98 foram aceitas. Além disso, colocamos uma rainha virgem marcada, proveniente de um casulo real de outra colônia. Esta rainha emergiu em uma estufa à $28^{\circ} \mathrm{C}$, um dia antes de ser introduzida na colonia. Iniciamos as observações a partir do momento em que a rainha fisogástrica foi substituída pela virgem.

As operárias continuaram a construir células normalmente e após 5 horas e 30 minutos, 31 células encontravam-se prontas (com colar). Não houve deposição de alimento nas mesmas.

De um modo geral, após observarmos vários dias esta colônia, pudemos verificar que houve construção e alimentação de células de cria; porém, a postura de operárias com posterior operculação foi um acontecimento raro.

No dia 09/08, notamos a presença de duas rainhas virgens, além daquela introduzida inicialmente na colonia. Uma delas permaneceu vários minutos parada no favo de cria mais velho. Algumas operárias tocavam o seu corpo e realizavam troca de alimento com ela.

$\mathrm{Na}$ entrada da colonia, não havia machos à espera da rainha virgem.

Em 15/08, notamos que a rainha marcada estava morta e coberta de cera, nos invólucros que recobriam os favos (do mesmo modo que o observado com a rainha fisogástrica, morta pelas operárias da colonia normal). Neste dia, observamos, também, uma rainha virgem tentando sair da colonia porém, era impedida pela tela excluidora. Havia um grupo de machos na entrada da colonia.

Em 18/08, não vimos mais nenhuma rainha virgem e por esta razão, em 22/08, colocamos três células reais na colonia e, em $27 / 08$, introduzimos uma outra rainha virgem marcada. No decorrer de todo o experimento, colocamos um total de cinco rainhas virgens e seis casulos reais.

Após alguns dias dentro da colonia, as rainhas tentavam sair para o voo nupcial. As operárias "forçavam" a saída das mesmas correndo atrás, tentando atacá-las com as mandrbulas. Depois de alguns dias, essas rainhas desapareciam sendo, possivelmente, mortas pelas operárias.

Observamos também que, quando uma rainha virgem corria pelo vidro da colonia, depositava uma secreção amarelada. As operárias ingeriam esta secreção.

\section{Divisão de trabalho.}

Em ambas as colônias (normal e com rainhas virgens), os trabalhos executados pelas operárias foram subdivididos em seis grupos de atividades que, em alguns casos, por serem muito relacionadas, foram os seguintes: a) trabalho com cera (construção de lamelas, invólucros, potes de pólen e mel, vedação de frestas e raspagem de cera das células de cria); b) trabalho com a cria (construção, aprovisionamento e operculação das células, inserção nas células durante o aprovisionamento, postura e corte à rai- 
nha); c) lixeira; d) receptoras de néctar (trabalhos cọm resina e desidrataçđo); e) guarda; f) campeira.

As operárias foram agrupadas em classes etárias e suas atividades foram dadas em porcentagem, como mostra a tabela 1 .

Através da comparação dos resultados obtidos (V. tabela 1), verificamos que o trabalho com cera iniciou-se em ambas as colonias na mesma faixa de idade, terminando quando as operárias atingiram os $\mathbf{3 0}$ dias (colonia com rainhas virgens) e aos $\mathbf{3 5}$ dias (colonia normal).

Os trabalhos com a cria foram bem diferentes nas duas colonias. Na normal, estas tarefas foram realizadas entre o 160 e 20 ọ dia de vida das abelhas. Já na colônia com rainhas virgens, estes trabalhos foram iniciados muito cedo, ou seja, do 5 ? ao 15 ? dia, com um pico abrangendo do 69 ao 10 ? dia de vida das operárias.

A atividade de lixeira foi mais marcante na colonia com rainhas virgens, tendo se iniciado, também, um pouco mais cedo, quando comparada com a colônia normal.

As tarefas relacionadas à desidratação e recepção do néctar, bem como as atividades com resina foram bem antecipadas na colonia com rainhas virgens (119 ao 25 ? dia de vida das abelhas).

A atividade de guarda foi inexistente na colonia com rainhas virgens.

Finalmente, os trabalhos de campo (coletas de poleon, néctar e resina) também iniciaram-se antes na colonia com rainhas virgens ( 110 ao 150 dia) tendo, também, terminado mais cedo ( 460 ao 50 o dia de vida das operárias).

A partir das observações diárias, pudemos calcular a longevidade média das operárias.

$\mathrm{Na}$ colónia normal, a taxa encontrada foi $39,5 \pm 9,8$ dias e na colônia com rainhas virgens foi $33,4 \pm 7,4$ dias.

\section{DISCUSSÃO E CONCLUSÕES}

Pelas observaçбes referentes ao processo natural de substituição de rainha, podemos sugerir que antes do ataque à rainha velha, já deveria existir uma nova rainha virgem, eleita pelas operárias. Esta hipótese é plenamente possível por doís motivos: 1. presença de uma rainha virgem na colonia treze dias antes da morte da rainha fisogástrica; as operárias lambiam o seu corpo e faziam uma corte típica de aceitação; 2. o inf́cio da postura da rainha nova deu-se após o 49 dia do ataque à rainha velha. Convém observar que este período é muito pequeno para que uma rainha possa passar por todo um processo de amadurecimento, ser fecundada e iniciar a postura das células. Devido à grande rapidez no processo de substituição (logo após a morte da rainha velha) até aventamos a hipótese da mesma já ter sido fecundada antes da morte da rainha mãe.

Silva, Zucchi \& Kerr (1972) e Silva (1972) demonstraram que em Melipona quadrifasciata e Plebeia (Plebeia) droryana uma rainha virgem é aceita antes da morte da rainha mãe. Estes autores sugerem que isso acontece devido à ausência de um dado feromonio que era anteriormente produzido pela rainha.

Com relação à determinadas características da substituição natural de rainha, constatamos que o ritual do ataque é bem diferente daquele descrito para outras espécies. 


\begin{tabular}{|c|c|c|c|c|c|c|c|c|c|c|c|c|c|}
\hline \multirow{3}{*}{\multicolumn{2}{|c|}{$\begin{array}{l}\text { Intervalo } \\
\text { de idade } \\
\text { das operárias } \\
\text { rias em } \\
\text { dias }\end{array}$}} & \multicolumn{12}{|c|}{ Freqüência (\%) de operárias nas diferentes atividades } \\
\hline & & \multicolumn{2}{|c|}{$\begin{array}{l}\text { Trabalho } \\
\text { com cera }\end{array}$} & \multicolumn{2}{|c|}{$\begin{array}{l}\text { Trabalho } \\
\text { na cria }\end{array}$} & \multicolumn{2}{|c|}{ Lixeira } & \multicolumn{2}{|c|}{$\begin{array}{l}\text { Desidrata- } \\
\text { dora e re- } \\
\text { ceptora }\end{array}$} & \multicolumn{2}{|c|}{ Guarda } & \multicolumn{2}{|c|}{ Campeira } \\
\hline & & $\mathbf{N}$ & $\mathbf{V}$ & $\mathbf{N}$ & V & $\mathbf{N}$ & $\mathbf{v}$ & $\mathbf{N}$ & $\mathbf{v}$ & $\mathbf{N}$ & $\mathbf{V}$ & $\mathbf{N}$ & v \\
\hline 0 & 5 & 56 & 62 & & 3 & & & & & & & 1 & \\
\hline 6 & 10 & 66 & 90 & & 21 & & & & & & & & \\
\hline 11 & 15 & 51 & 73 & & 2 & & & & 4 & & & & 3 \\
\hline 16 & 20 & 58 & 55 & 21 & & & 6 & & 16 & & & & 2 \\
\hline 21 & 25 & 37 & 36 & & & 1 & 48 & 3 & 5 & & & & 8 \\
\hline 26 & 30 & 20 & 8 & & & 4 & 41 & 4 & & & & 2 & 57 \\
\hline & 35 & 5 & & & & 2 & 11 & 13 & & 7 & & 9 & 68 \\
\hline 36 & 40 & & & & & & & 28 & & 3 & & 27 & 47 \\
\hline & 45 & & & & & & & 3 & & & & 38 & 12 \\
\hline 46 & 50 & & & & & & & & & & & 14 & 1 \\
\hline 51 & 55 & & & & & & & & & & & 10 & \\
\hline 56 & 60 & & & & & & & & & & & 1 & \\
\hline
\end{tabular}

TABELA 1 Freqüência em porcentagem de operárias de S. postica nas principais atividades, em cada classe etária na colônia normal $(\mathrm{N})$ e na colônia com rainhas virgens $(\mathrm{V})$.

Imperatriz-Fonseca (1977) verificou que a substituição da rainha fisogástrica em colônias de Paratrigona subnuda dá-se do seguinte modo: a rainha virgem, que tenta substituir a fisogástrica, excreta fezes e, principalmente, uma substância pela mandibula sobre o corpo da mesma; a rainha fisogástrica não se defende. Muitas vezes, ela própria procura espalhar essas excreções pelo seu corpo, através das suas patas anteriores. As operárias lambem toda a excreção da rainha virgem sobre o corpo da fisogástrica, até que esta provavelmente fica sem atratividade. Quando isso ocorre, as operárias iniciam o ataque, picando a rainha em várias partes. Após este processo, a rainha virgem sairá para o voo nupcial, passando antes por um período de repouso.

Em Plebeia (P.) droryana, a rainha virgem, eleita pelas operárias, ajuda no ataque à rainha mãe, sendo esta também picada em várias partes (Silva 1972).

Com referência aos aspectos relacionados à colonia com rainhas virgens, verificamos que as gotículas de substância amarela expelidas pelas rainhas virgens parecem estar ligadas a atratividade das mesmas (V. Imperatriz-Foneca 1977) em Paratrigona submuda). Silva, Zucchi \& Kerr (1972) também observaram o mesmo fenômeno em rainhas virgens de Melipona quadrifasciata anthidioides. É possivel que essa secreção seja um controle feromonal por parte dessas rainhas. 
Várias rainhas de $S$. postica podem permanecer na colonia sem ocorrer hostilidades. No entanto, em Melipona quadrifasciata, a rainha virgem selecionada que irá substituir a rainha mãe, ajuda no ataque de outras rainhas virgens (Silva, Zucchi \& Kerr 1972).

Com relação à atratividade das rainhas virgens, verificamos que se trata de um processo gradativo. Quando novas, não atraem machos para a entrada da colônia. Somente quando atingem uma certa idade é que os machos se agregam nas proximidades da entrada do ninho. Esse fato é bastante interessante porque mostra que o odor da rainha virgem aumenta com a idade, podendo, assim, atrair machos a uma distância considerável.

Quando à longevidade das rainhas virgens, notamos apenas que podem permanecer por vários dias na colônia. Possivelmente, depois de algum tempo, são mortas pelas operárias. Nossos dados reforçam aqueles obtidos por Hebling, Kerr \& Kerr (1964). Estes autores demonstraram que as rainhas virgens de $S$. xanthotricha podem permanecer por aproximadamente um mês dentro da colonia e, posteriormente, são atacadas pelas operárias.

Pelo estudo realizado sobre a divisão de trabalho entre as operárias da colônia normal e com rainhas virgens, observamos que existe uma seqüência preferencial na distribuição das tarefas, ou seja: com cera, na cria, lixeira, receptora e desidratadora, guarda e campeira.

Ao que pudemos constatar, a quebra da normalidade da colonia altera o início de várias atividades. Assim, na colônia com rainhas virgens, que representa um estado anormal da colônia, há um desequilíbrio nas tarefas realizadas pelas operárias. A antecipação da maioria das atividades pode ser devida a uma diminuição acentuada nos trabalhos relacionados com a cria (construção, aprovisionamento e postura das células de cria).

Esses dados evidenciam que, de acordo com as condiçбes específicas das colô. nias (necessidades das mesmas), as tarefas não são estritamente dependentes da idade.

Comparando os nossos resultados com os trabalhos de Sakagami (1953) em Apis mellifera, Darchen (1969) em Apotrigona nebulata, Hebling, Kerr \& Kerr (1964) em Scaptotrigona xanthotricha, Kerr \& Santos Neto (1956) em Melipona quadrifasciata, verificamos que a seqüência das atividades desenvolvidas pelas operárias dessas espécies são semelhantes. As diferenças encontradas referem-se apenas à idade em que as atividades são desenvolvidas.

Lindauer (1952 in Free 1965) tenta explicar o mecanismo da divisão de trabalho. Este autor demonstra que as abelhas caseiras permanecem sem atividade por horas $e$, freqüentemente, vagueiam sobre o favo, inspecionando as células de cria. Essa atividade foi denominada de "patrulha", sendo que, na realização do patrulhamento, as operárias colhem informaçбes dos trabalhos que necessitam fazer. Possivelmente, o estímulo encontrado libera o comportamento padrão fisiológico e psicológico, conveniente para as abelhas.

Os dados referentes à longevidade média das operárias da colônia normal foi maior em relação à colônia com rainhas virgens. É possível que tal diferença esteja diretamente correlacionada à tarefa de campeira, que nesta última colônia deu-se mais cedo; sabe-se que, nesta fase, os riscos ecológicos são maiores. 
É importante ressaltar que, mesmos em colônias normais, a longevidade média das operárias varia. Simões (1974) verificou que tais diferenças podem estar ligadas às condições internas da colônia. Ceccato (1970) observou que as operárias de Melipona rufiventris flavolineata são mais ativas na estação quente em relação à quase todas as tarefas realizadas. Além disso, a longevidade dessas abelhas é maior quando comparadas com as abelhas de estação fria.

Na literatura existem vários dados sobre a longevidade média de alguns meliponíneos, tais como: S. xanthotricha - 92 dias (Hebling, Kerr \& Kerr 1964), Melipona quadrifasciata - 43 dias (Kerr \& Santos Neto 1956), Frisiomelitta silvestri - 120 dias (Kerr informação pessoal).

Os dados de $S$. postica revelam que a longevidade média das operárias é menor em relação às citadas acima.

Nossos resultados sobre divisão de trabalho e longevidade média das operárias sugerem que as alteraçס̃es ocorridas na colônia com rainhas virgens podem estar ligadas ao desequilíbrio interna da colônia. No entanto, é necessário ainda realizar um maior número de observaçōes para que se possa chegar a uma conclusão definitiva dos mecanismos que estão envolvidos nesse processo.

\section{AGRADECIMENTOS}

Agradecemos ao Prof. Dr. Ronaldo Zucchi e Dr. Schôichi F. Sakagami pelas sugestões dadas e a FAPESP (Fundação de Amparo à Pesquisa do Estado de São Paulo) por ter financiado o trabalho.

\section{BIBLIOGRAFIA}

BASSINDALE, R. 1955 The biology of the stingless bee Trigona (Hypotrigona) gribodai Magretti (Meliponidae). Proc. Zool. Soc. London. 125: 49-62.

DARCHER, R. 1969 Sur la biologie de Trigona (Apotrigona) nebulata komiensis Cock I. Biologia Gabonica. 3 (5): 151-187.

CECCATO, S. 1970 - Divisāo de trabalho entre as operárias de Melipona rufiventris flavolineata Friese (Hym., Apoidea). Dissertação de Mestrado. Departamento de Zoologia. Instituto de Biociências (USP). São Paulo. 30 pp.

FREE, J.B. 1965 The allocation of duties among workers honeybess. Symp. Zool. Soc. Lond. 14: 39-59.

HEBLING, N.J.; W.E. KERR \& F.S. KERR. 1964 Divisão de trabalho entre operárias de Trigone (Scaptotrigona) xanthotricha Moure. Papéis Avulsos Zool. S.P. 16 (15): 115-127.

IMPERATRIZ-FONSECA, V.L. 1977 Studies of Paratrigona subnuda (Moure) Hymenoptera Apidae, Meliponinae) II Behaviour of the virgin queen. Bolm. Zool., Univ. S. Paulo. 2 169-182. 
KERR, W.E. \& G.R. SANTOS NETO 1956 Contribuição para o conhecimento da bionomia dos Meliponini. 5. Divisão de trabalho entre as operárias de Melipona quadrifasciata quadrifasciata. Lep. Insectes Sociaux. 3 (3): 423-430.

SAKAGAMI, S.F. 1953 Untersuchugen über die Arbeitsteilung in einem Zwergvolk der Honigbiene. Beitrage zur Biologie des Bienenvolkes, Apis mellifera L., I. Jap. J. Zool. 11 (1): 117-185.

SAKAGAMI, S.F. 1966 Techniques for the observation of behavior and social organization of stingles bees by using a special hive. Papéis Avulsos Zool. S.P. 19: 151-162.

SAKAGAMI, S.F. and R. ZUCCHI 1963 - Oviposition process in a stingless bee, Trigona (Scaptotrigona) postica (Latr. (Hym.). Studia Ent. 6 (1-4): 497-510.

SEKIGUCHI, R. and S.F. SAKAGAMI 1966 - Structure of foraging population and related problems in the honey bee, with considerations on the division of labour in bee colonies. Hokkaido Nat. Agric. Exp. Station. Sapporo, Japan. 69: 1-65.

SILVA, D.L.N. 1970 - Sobre a divisão de trabalho entre operárias de Melipone marginata Lep. XXII Reunião Anual. Ciência e Cultura 22: 289.

SILVA, D.L.N. 1972 Consideraçð̃es em torno de um caso de substituição de rainha em Plebeia (Plebeia) droryana (Friese, 1900) (Hymenoptera, Apidae). Volume em Homenagem a Warwick E. Kerr. pp. 267-273.

SILVA, D.L.N.; R. ZUCCHI and W.E. KERR 1972 - Biological and behavioural aspects of the reproduction in some species of Melipona (Hymenoptera, Apidae, Meliponinae). Anim. Behav. 20 (1): $123-132$.

SIMÕES, D. 1974 Estudos sobre regulação social em Nannotrigona (Scaptotrigona) postica (Latreille, com especial referência aos aspectos comportamentais (Hym., A pidae, Meliponinae). Dissertação de Mestrado. Departamento de Genética da Faculdade de Medicina de Ribeirão Preto (USP). 92 pp. 
